13

\title{
Интеркалирование графена на карбиде кремния кобальтом
}

\author{
(С Г.С. Гребенюк ${ }^{1}$, Е.Ю. Лобанова ${ }^{2}$, Д.А. Смирнов ${ }^{3,4}$, И.А. Елисеев ${ }^{1}$, А.В. Зубов ${ }^{2}$, \\ А.Н. Смирнов ${ }^{1}$, С.П. Лебедев ${ }^{1}$, В.Ю. Давыдов ${ }^{1}$, А.А. Лебедев ${ }^{1}$, И.И. Пронинн ${ }^{1,2}$ \\ ${ }^{1}$ Физико-технический институт им. А.Ф. Иофффе, \\ Санкт-Петербург, Россия \\ ${ }^{2}$ Санкт-Петербургский национальный исследовательский университет \\ информационных технологий, механики и оптики, \\ Санкт-Петербург, Россия \\ ${ }^{3}$ Санкт-Петербургский государственный университет, \\ Санкт-Петербург, Россия \\ ${ }^{4}$ Institute of Solid State Physics, Dresden University of Technology, \\ Dresden, Germany \\ E-mail: Igor.Pronin@mail.ioffe.ru
}

Поступила в Редакцию 13 марта 2019 г.

В окончательной редакции 13 марта 2019 г.

Принята к публикации 15 марта 2019 г.

Исследован процесс интеркалирования кобальтом однослойного графена, выращенного на политипе $4 H$-SiC(0001). Эксперименты проведены in situ в условиях сверхвысокого вакуума методами фотоэлектронной спектроскопии высокого энергетического разрешения с использованием синхротронного излучения и дифракции медленных электронов. Номинальные толщины наносимых слоев кобальта варьировались в диапазоне $0.2-5 \mathrm{~nm}$, а температура образцов — от комнатной до $800^{\circ} \mathrm{C}$. Показано, что отжиг пленок $\mathrm{Co}$, напыленных на графен при комнатной температуре, в отличие от пленок $\mathrm{Fe}$, не приводит к интеркалированию графена кобальтом. Формирование интеркаляционной системы графен-кобальт-SiC обнаружено при нанесении атомов Со на образцы, нагретые до температур выше $\sim 400^{\circ} \mathrm{C}$. Этим способом под графеном сформированы пленки кобальта толщиной до $2 \mathrm{~nm}$ и показано, что они намагничиваются вдоль поверхности при толщинах более $1.3 \mathrm{~nm}$. Обнаружено, что интеркалирование графена кобальтом сопровождается химическим взаимодействием атомов Со с карбидом кремния, приводящим к синтезу силицидов кобальта. При температурах более $500^{\circ} \mathrm{C}$ рост пленок кобальта под графеном лимитируется диффузией атомов Со в объем карбида кремния.

Ключевые слова: графен на карбиде кремния, кобальт, интеркаляция, ферромагнитные пленки, фотоэлектронная спектроскопия.

DOI: 10.21883/FTT.2019.07.47854.416

\section{1. Введение}

Карбид кремния является одним из наиболее перспективных материалов для формирования графена. Успешное развитие метода сублимации кремния из монокристаллических подложек $\mathrm{SiC}[1,2]$ сделало возможным не только выращивание высококачественного эпитаксиального графена на поверхности этого материала, но и устранило проблему переноса выращенной пленки на диэлектрическую подложку, которая часто возникает при использовании пленок графена, синтезированного на металлах. Большим преимуществом развитого метода является и возможность формирования графена на поверхности коммерческих подложек большого размера, что открывает перспективу интегрирования графена в стандартную технологическую линейку изготовления полупроводниковых приборов. Однако создание на основе графена новых электронных приборов требует также разработки методов контролируемого изменения его свойств. Одним из возможных способов модификации графена является его интеркалирование чужеродными атомами, то есть внедрение их в простран- ство между графеном и подложкой [3-5]. Такой способ позволяет формировать разнообразные интеркаляционные системы, в частности, структуры типа графенферромагнитный-металл, в которых наблюдаются такие явления, как индуцированный магнетизм и усиление перпендикулярной магнитной анизотропии [6-10]. Эти структуры представляют большой научный интерес и перспективны для реализации графеновой спинтроники [11]. Поэтому контакт графена с металлами группы железа стал объектом активных исследований в последние годы [12-26]. Однако большая часть этих работ выполнена для графена, выращенного на поверхности металлов методом химического осаждения из газовой фазы. Что же касается графена на карбиде кремния, к настоящему времени опубликовано лишь несколько работ по его интеркалированию железом [20-22] и кобальтом [23-26], и в литературе имеется недостаток данных по этим сложным системам. В особенности это касается системы графен-кобальт- $\mathrm{SiC}(\mathrm{Gr} / \mathrm{Co} / \mathrm{SiC})$. Действительно, отмеченные выше работы $[23,24]$ затрагивают лишь проблему формирования монодисперсных кластеров Со на реконструированной поверхности 
$6 H$ - $\mathrm{SiC}(0001)$, а недавно опубликованные статьи $[25,26]$ посвящены процессам, протекающим при отжиге ультратонких (толщиной $\sim 1$ монослоя) [25] и более толстых пленок кобальта $(0.4-12 \mathrm{~nm})$ [26], сформированных на той же поверхности при комнатной температуре. В настоящей работе мы впервые исследовали интеркалирование кобальтом графена, выращенного на поверхности политипа $4 H-\mathrm{SiC}(0001)$. Целью работы было изучение эволюции атомного строения, элементного и фазового состава интерфейса $\mathrm{Gr} / \mathrm{Co} / \mathrm{SiC}$, а также его магнитных свойств с увеличением дозы интеркалирования графена кобальтом и с повышением температуры. Сопоставление полученных результатов с данными для исследованной нами ранее в тех же условиях системы $\mathrm{Gr} / \mathrm{Fe} / \mathrm{SiC}$ [22] позволило выявить специфику физико-химических процессов, протекающих в этих системах при повышенных температурах.

\section{2. Техника эксперимента}

Графен на поверхности карбида кремния формировался методом термического разложения поверхности $\mathrm{SiC}$ в среде инертного газа (аргона) [27]. Эта технология позволяет оптимизировать процесс сублимации компонентов карбида кремния и осуществлять контролируемый рост эпитаксиального графена. Графен выращивался на высокоомных пластинах $\mathrm{SiC}$ политипа $4 H$ размером $5 \times 5 \mathrm{~mm}$. В работе использовалась серия идентичных образцов, на поверхности которых был сформирован монослойный графен высокого качества с небольшой долей $(\sim 15 \%)$ включений двухслойных островков с субмикронными размерами.

Исследования структурных характеристик образцов проводилось методом комбинационного рассеяния света (КРС). Измерения выполнялись при комнатной температуре на спектрометрической установке Т64000, укомплектованной конфокальным микроскопом, что позволяло получать информацию из области графеновой пленки диаметром $1 \mu \mathrm{m}$. Для оценки однородности структурных характеристик измерения производились в центре и четырех равноудаленных от центра точках образца. Для возбуждения спектров КРС использовался твердотельный $\mathrm{Nd}$ :YAG-лазер $\left(\lambda_{\mathrm{ex}}=532 \mathrm{~nm}\right)$, мощность лазерного излучения на образце равнялась $2.0 \mathrm{~mW}$. Bce спектры КРС графеновых пленок, приводимые в работе, получены после вычитания вклада спектра подложки $4 H-\mathrm{SiC}$.

Основные эксперименты по интеркалированию графена кобальтом проводились на фотоэмиссионной станции RGBL-PES Российско-Германского дипольного канала вывода синхротронного излучения накопительного кольца BESSY II (г. Берлин). Они были выполнены in situ в условиях сверхвысокого вакуума. На первой стадии экспериментов образцы подвергались очистке длительным прогревом при температуре $500^{\circ} \mathrm{C}$. Интеркалирование графена кобальтом проводилось путем нанесения атомов Со на поверхность образцов при различных темпе- ратурах, варьировавшихся в диапазоне от комнатной до $600^{\circ} \mathrm{C}$. При этом каждая серия экспериментов, в которой исследовалась эволюция системы $\mathrm{Gr} / \mathrm{Co} / \mathrm{SiC}$ с увеличением дозы интеркалирования графена кобальтом, начиналась с нового образца. Напыление пленок кобальта осуществлялось с помощью электронно-лучевого источника фирмы Omicron со скоростью $0.1 \mathrm{~nm} / \mathrm{min}$. Вакуум при работе источника был не хуже, чем $2 \cdot 10^{-9}$ mbar. Номинальная толщина пленок, наносимых на поверхность образцов, контролировалась с помощью кварцевых микровесов и варьировалась в диапазоне $0.2-5 \mathrm{~nm}$.

Контроль элементного и химического состава поверхности образцов, а также их атомного строения проводился методами фотоэлектронной спектроскопии высокого энергетического разрешения и дифракции медленных электронов (ДМЭ). Энергия фотонов варьировалась в интервале $135-650 \mathrm{eV}$. Спектры фотоэлектронов регистрировались с помощью полусферического энергоанализатора электронов SPECS PHOIBOS 150. Полное энергетическое разрешение прибора (включая разрешение монохроматора) составляло $100 \mathrm{meV}$.

Исследование магнитных свойств пленок кобальта, сформированных под графеном, проводилось in situ с помощью этого же энергоанализатора методом магнитного линейного дихроизма (МЛД) в угловом распределении остовных Со $3 p$ электронов. Пучок линейнополяризованного света падал на поверхность образца под углом $30^{\circ}$, а регистрация электронов проводилась вдоль нормали к поверхности. Намагничивание образцов осуществлялось с помощью пары катушек Гельмгольца, находившихся внутри вакуумной камеры. Пропусканием через них импульсов тока создавались вертикальные магнитные поля $H_{\text {up }}$ и $H_{\text {down }}$ напряженностью 1000 Ое, параллельные поверхности образца. Спектры измерялись в режиме остаточной намагниченности при комнатной температуре и давлении остаточных газов $5 \cdot 10^{-10}$ mbar.

\section{3. Результаты и их обсуждение}

Данные, демонстрирующие качество исходной пленки графена, представлены на рис. 1 и 2. На рис. 1,a показана типичная картина ДМЭ, полученная при энергии электронов $76.5 \mathrm{eV}$. В ней хорошо видна структура $(6 \sqrt{ } 3 \times 6 \sqrt{ } 3) R 30^{\circ}$, характерная для карбида кремния, покрытого однослойным графеном [28]. Она возникает вследствие несовпадения периодов решеток графена и реконструированной поверхности карбида кремния. Четкость рефлексов свидетельствует о строгой упорядоченности кристаллической структуры графена и подложки.

На рис. 2, $а$ приведен обзорный спектр фотоэлектронов, измеренный при энергии фотонов $650 \mathrm{eV}$ для контроля элементного состава поверхности образца после его очистки в вакууме. Спектр имеет стандартный вид. В нем присутствуют лишь линии углерода и кремния, 


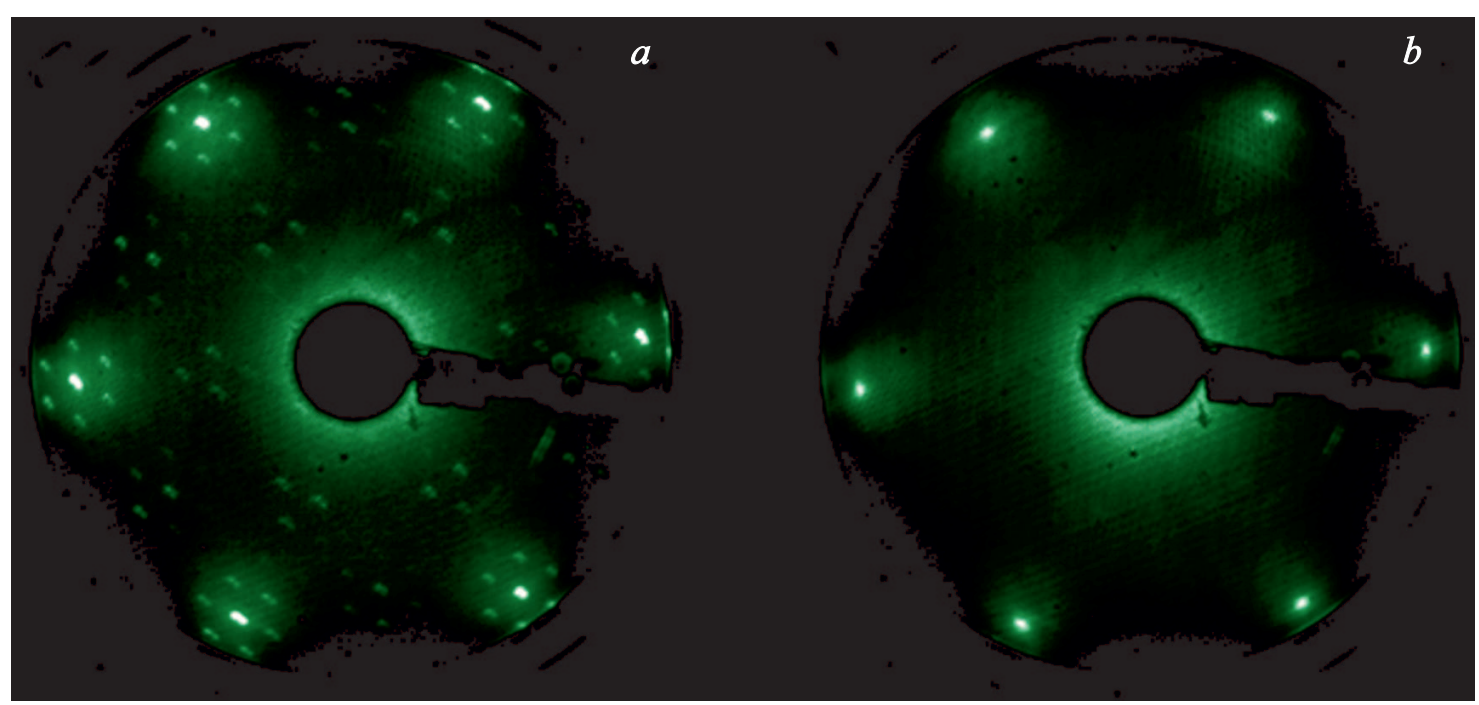

Рис. 1. Картины ДМЭ, полученные при энергии $76.5 \mathrm{eV}: a-$ картина образца $\mathrm{Gr} / \mathrm{SiC}$ с чистой поверхностью, $b-$ картина, наблюдавшаяся после интеркалирования.

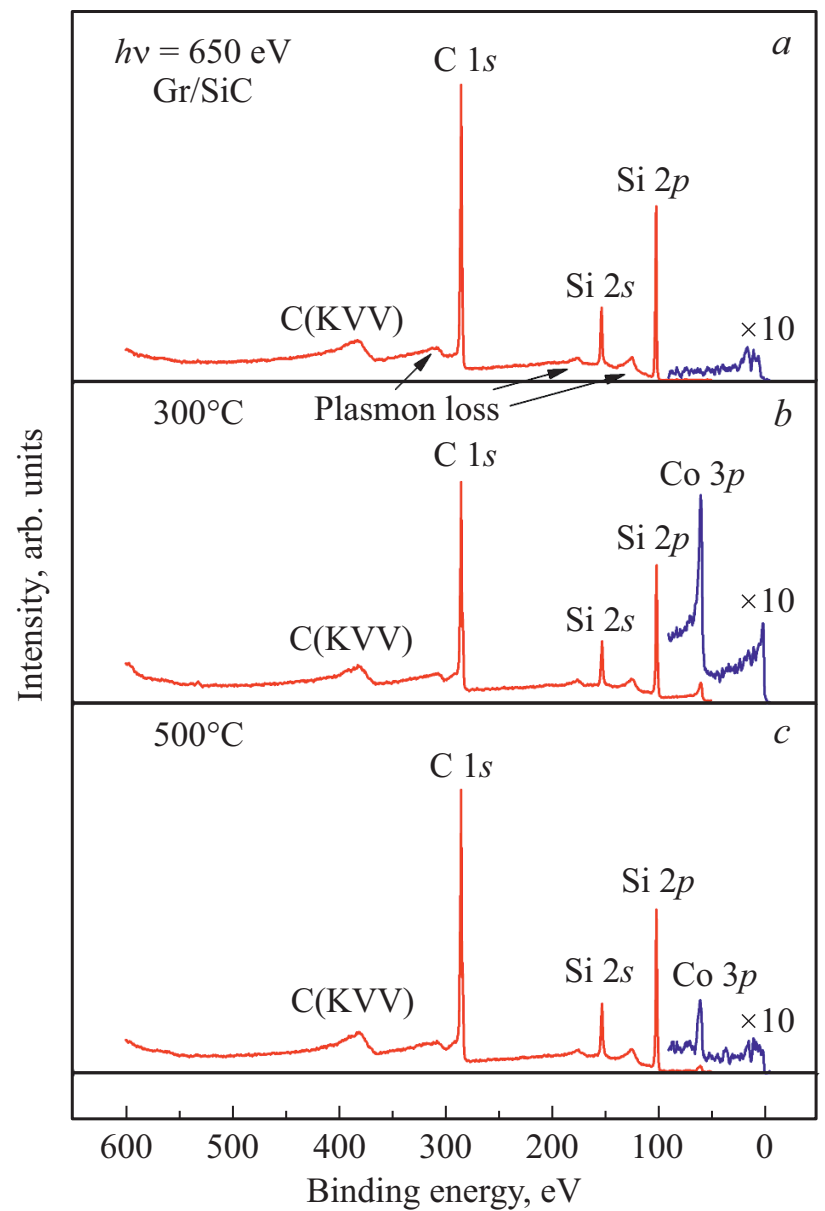

Pис. 2. Обзорные спектры фотоэлектронов, измеренные для образца $\mathrm{Gr} / \mathrm{SiC}$ с чистой поверхностью $(a)$ и образцов, на которые напылялось $0.3 \mathrm{~nm}$ кобальта при температурах $300^{\circ} \mathrm{C}(b)$ и $500^{\circ} \mathrm{C}(c)$. а также сопутствующие им пики характеристических потерь энергии электронов.

Особый интерес представляет спектральная линия $\mathrm{C} 1 \mathrm{~s}$, наиболее чувствительная к состоянию графена. Спектр $\mathrm{C} 1 \mathrm{~s}$, измеренный после очистки образца (рис. 3,a), хорошо согласуется с литературными данными для однослойного графена на карбиде кремния $[20,22,27]$. Линия C 1 s состоит из четырех компонент [29], показанных на рисунке. Наиболее интенсивная из них (мода $G$ ) соответствует графену. Вторая компонента $(\mathrm{SiC})$ связана с атомами углерода в карбиде кремния. Наконец, моды $S_{1}$ и $S_{2}$ обусловлены наличием двух типов атомов углерода в буферном слое, находящемся между графеном и верхним слоем атомов $\mathrm{SiC}(0001)$. При этом компонента $S_{1}$ относится к тем атомам углерода, которые связаны висячими связями с нижележащим слоем $\mathrm{SiC}$, а мода $S_{2}$ соответствует атомам углерода, не связанным с этим слоем. Согласно работе [29] интенсивность моды $S_{2}$ должна быть в два раза больше, чем интенсивность моды $S_{1}$. Как видно из рис. $3, a$, именно такое соотношение интенсивности компонент характерно для приведенного спектра.

Рассмотрим теперь результаты, полученные в первой серии экспериментов, в которой кобальт напылялся на поверхность образца при комнатной температуре. Нанесение на графен $0.2 \mathrm{~nm}$ Со привело к формированию на нем островковой пленки кобальта, поглощение потока фотоэлектронов в которой снизило интенсивность линии $\mathrm{C} 1 \mathrm{~s}$ на $30 \%$. В той же мере затухли и все другие линии подложки. Это свидетельствует о том, что при комнатной температуре процесс интеркалирования графена кобальтом не протекает. Справедливость такого вывода подтверждается и неизменностью формы линии спектров $\mathrm{C} 1 \mathrm{~s}$, показанных на рис. $3, a$ и 3, $b$. Соответствующие им кривые практически полностью совпадают. 


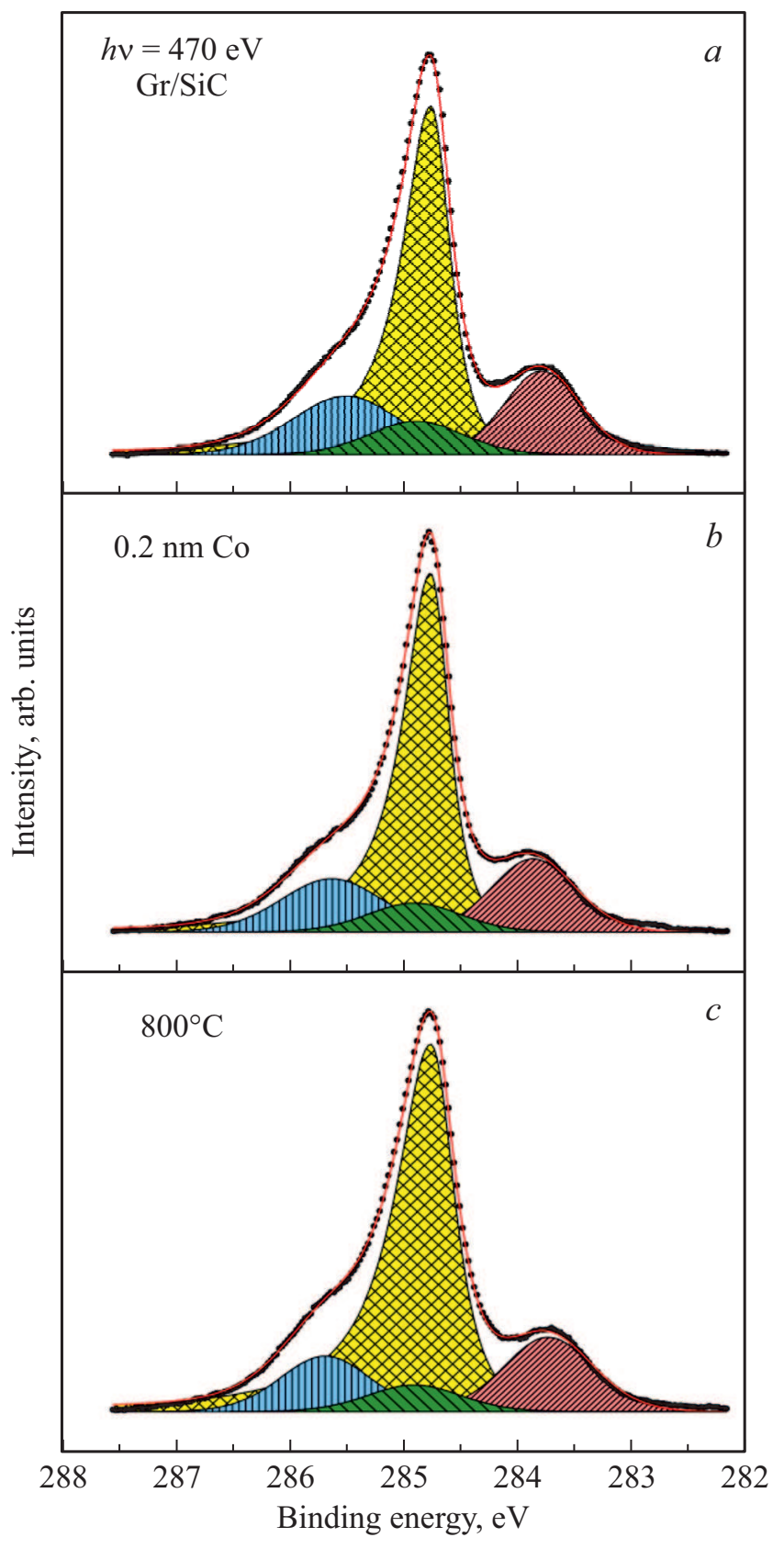

Рис. 3. Спектры C $1 s$, измеренные для образца $\mathrm{Gr} / \mathrm{SiC}$ с чистой поверхностью $(a)$, после напыления на него $0.2 \mathrm{~nm}$ кобальта при комнатной температуре $(b)$ и 10-минутного отжига при $800^{\circ} \mathrm{C}(c)$.

Для активации процесса интеркалирования образец с нанесенной пленкой кобальта был подвергнут 10-минутному отжигу при температуре $450^{\circ} \mathrm{C}$, который оптимален для инициирования аналогичного процесса в системе $\mathrm{Gr} / \mathrm{Fe} / \mathrm{SiC}$ [22]. Однако и после такого отжига никаких признаков интеркалирования графена кобальтом обнаружить не удалось. Поэтому далее температура образца была повышена до значений $600^{\circ} \mathrm{C}$ и $800^{\circ} \mathrm{C}$, при которых в системе $\mathrm{Gr} / \mathrm{Fe} / \mathrm{SiC}$ уже протекает химическое взаимодействие интеркалированного железа с карбидом кремния. Эти высокотемпературные отжиги также не привели к проникновению атомов кобальта под графен. После них в спектрах наблюдалось лишь частичное синхронное восстановление интенсивности линий углерода и кремния, характерное для морфологической перестройки пленки $\mathrm{Co}$, приводящей к укрупнению островков. При этом форма линии спектров C 1s (cм. рис. $3, c)$ и $\mathrm{Si} 2 p$, по-прежнему, оставалась неизменной. Сходные результаты дали и эксперименты, в которых отжигались более толстые пленки кобальта (толщиной 0.6 и $1.0 \mathrm{~nm})$. Все эти данные свидетельствуют о существенном различии миграционных процессов атомов железа и кобальта на поверхности графена, покрытого островковыми пленками этих металлов.

В следующих сериях экспериментов кобальт наносился на поверхность нагретых образцов. Полученные результаты иллюстрируются рис. 2,b и 2,c. На них показаны обзорные спектры, измеренные после напыления $0.3 \mathrm{~nm}$ Со на образцы, имевшие температуры 300 и $500^{\circ} \mathrm{C}$. Видно, что напыление Со при $300^{\circ} \mathrm{C}$ приводит к значительному затуханию (на 25\%) линии C1s. Это говорит о том, что при данной температуре на графене по-прежнему формируется пленка кобальта. Однако при $500^{\circ} \mathrm{C}$ (рис. 2,c) заметного затухания пика $\mathrm{C} 1 \mathrm{~s}$ уже не наблюдается, и в этих условиях протекает интеркалирование графена кобальтом, который уходит с поверхности в более глубокие слои, о чем говорит снижение интенсивности линии Со $3 p$ на рис. 2, $c$ по сравнению с рис. $2, b$.

Анализ всех полученных данных показал, что область температур, пригодных для интеркалирования графена кобальтом, довольно ограничена. В области низких температур она начинается примерно с $400^{\circ} \mathrm{C}$. При этом, наряду с интеркалированием системы, наблюдается также рост пленки кобальта на графене. При температурах же более $500^{\circ} \mathrm{C}$ формирование пленок кобальта под графеном ограничивается диффузией атомов Со в объем карбида кремния. Таким образом, оптимальной является температура около $450^{\circ} \mathrm{C}$.

Данные, иллюстрирующие процесс интеркалирования графена кобальтом при температуре $450^{\circ} \mathrm{C}$, представлены на рис. 4. На нем показаны типичные спектры $\mathrm{C} 1 \mathrm{~s}$, полученные при энергии фотонов 470 и $650 \mathrm{eV}$. Кроме измеренных спектров на рисунке представлены и результаты их разложения на составляющие. Сопоставление спектров чистого графена, полученных при двух энергиях фотонов, наглядно демонстрирует более высокую поверхностную чувствительность спектра при $470 \mathrm{eV}$ (для которого наблюдается усиление моды $G$ графена) по сравнению со спектром, измеренным при энергии $650 \mathrm{eV}$. Из рисунка также хорошо видно, что напыление $0.3 \mathrm{~nm}$ Со приводит к заметному ослаблению мод карбида кремния $(\mathrm{SiC})$ и буферного слоя $\left(S_{1}\right.$ и $\left.S_{2}\right)$ относительно моды графена. Это свидетельствует о том, что в ходе напыления, действительно, происходит интеркалирование графена, и под ним формируется слой кобальта, который поглощает поток фотоэлектронов из 


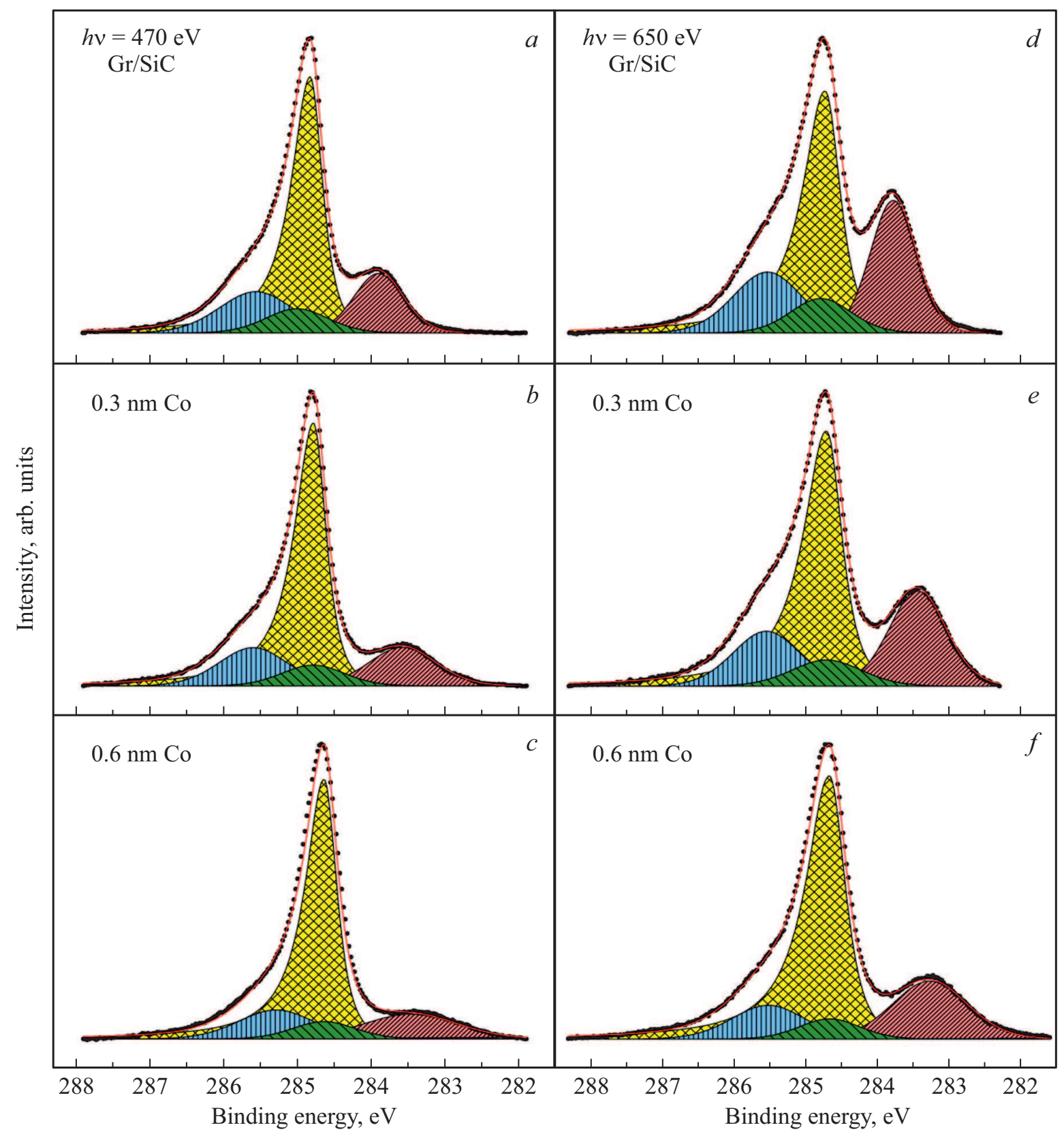

Рис. 4. Спектры C $1 s$, измеренные на разных стадиях процесса интеркалирования графена кобальтом при энергиях фотонов 470 и $650 \mathrm{eV}$, и результаты их разложения на составляющие.

$\mathrm{SiC}$ и буферного слоя. Увеличение дозы напыления до $0.6 \mathrm{~nm}$ Со приводит к росту более толстой пленки кобальта под графеном и к дальнейшему ослаблению мод $\mathrm{SiC}, S_{1}$ и $S_{2}$ в спектрах, измеренных при обеих энергиях фотонов (рис. 4).

Интеркалирование графена кобальтом оказывает существенное влияние и на спектры кремния. Характерные спектры $\mathrm{Si} 2 p$ электронов приведены на рис. 5. Для получения информации о распределении по глубине атомов кремния, находящихся в разных химических состояниях, спектры измерялись при энергиях фотонов, обеспечивавших более высокую $(135 \mathrm{eV})$ и менее высо- кую $(470 \mathrm{eV})$ поверхностную чувствительность метода. Исходные спектры графена на карбиде кремния (верхние кривые) имеют стандартный вид и согласуются с данными работ [26,28]. Кроме основной компоненты, соответствующей атомам $\mathrm{Si}$ из карбида кремния, в них имеется мода $S$ атомов кремния, контактирующих с буферным слоем и слабая дефектная мода $D$. Нанесение $0.3 \mathrm{~nm}$ Со при температуре $450^{\circ} \mathrm{C}$ приводит, во-первых, к затуханию линии кремния (на 35\% при $135 \mathrm{eV}$ и $31 \%$ при $470 \mathrm{eV}$ ), вызванному поглощением $\mathrm{Si} 2 p$ электронов в слое интеркалированного кобальта, а во-вторых, к изменению формы линии спектра. На рис. 5, 


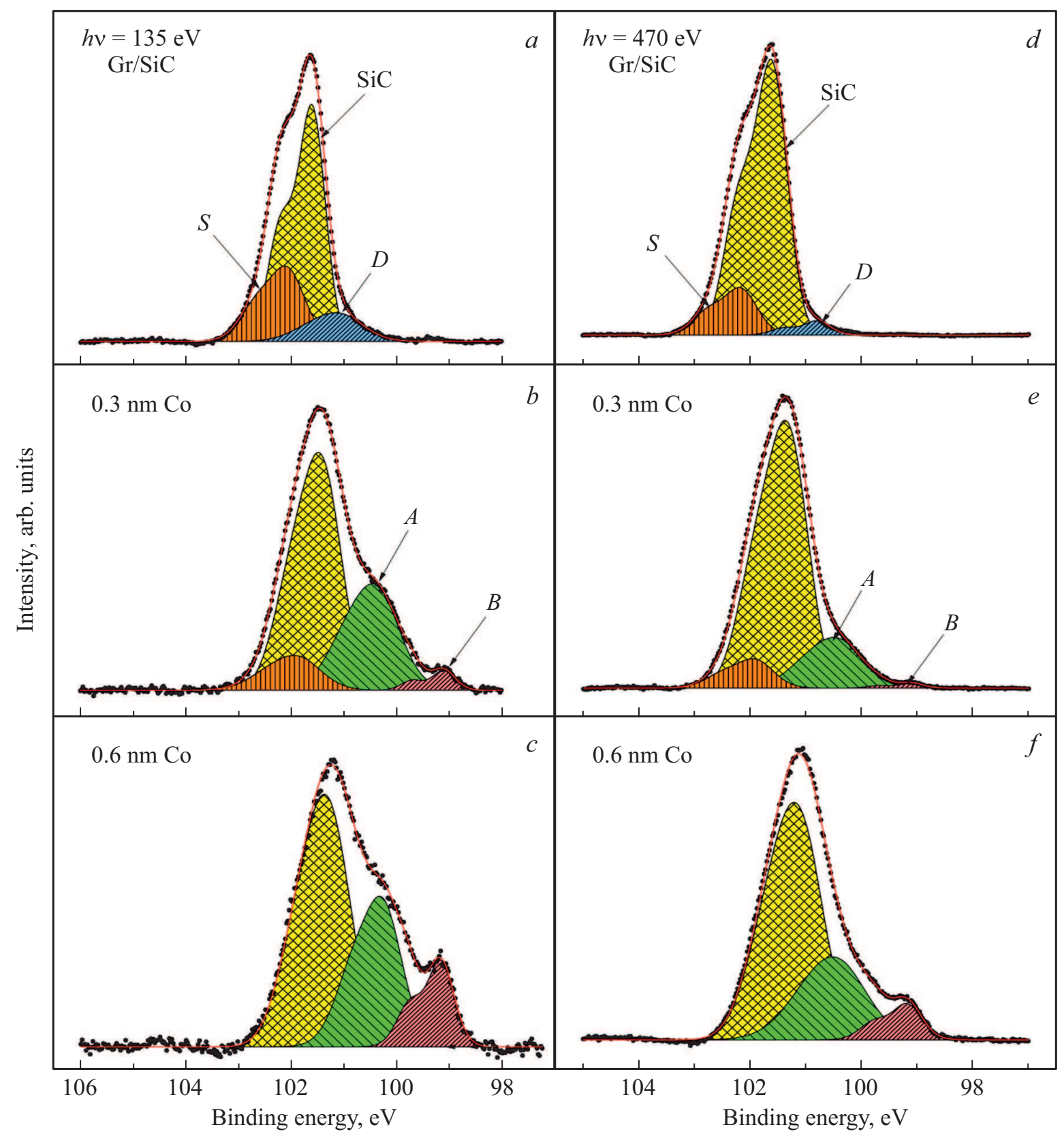

Рис. 5. Спектры Si $2 p$, измеренные на разных стадиях процесса интеркалирования графена кобальтом при энергиях фотонов 135 и $470 \mathrm{eV}$, и результаты их разложения на составляющие.

в соответствии с результатами работы [26], хорошо видны уширение основной компоненты $\mathrm{SiC}$, уменьшение интенсивности моды $S$, исчезновение моды $D$ и появление новых компонент $A$ и $B$, характерных для силицидов кобальта. Так как в спектрах, измеренных при $135 \mathrm{eV}$, эти новые моды выражены сильнее, чем при $470 \mathrm{eV}$, можно сделать вывод, что формирование силицидов кобальта происходит в приповерхностной области образца. Причиной их возникновения является химическое взаимодействие интеркалированного кобальта с карбидом кремния. Интенсивность силицидных компонент спектра не велика, но их появление сви- детельствует о менее высокой термической стабильности интерфейса $\mathrm{Co} / \mathrm{SiC}$ по сравнению с границей раздела $\mathrm{Fe} / \mathrm{SiC}$ [22]. Повышение дозы интеркалирования графена кобальтом до $0.6 \mathrm{~nm}$, хоть и усиливает силицидные моды Si $2 p$ спектров, но приводит лишь к незначительному увеличению толщины силицидной пленки, которая достигает примерно $0.1 \mathrm{~nm}$ и почти не растет при дальнейшем интеркалировании графена кобальтом. Эти данные также согласуются с результатами работы [26].

Формирование под графеном пленок кобальта и силицидов кобальта в результате напыления металла на 
нагретый образец отчетливо проявляется и в картинах ДМЭ. Типичная картина, наблюдавшаяся после напыления $0.8 \mathrm{~nm} \mathrm{Co}$, приведена на рис. 1, $b$. Сравнение ее с исходной картиной показывает, что рефлексы, соответствующие карбиду кремния, в ней почти исчезают, а остаются лишь рефлексы, обусловленные графеном. Однако с увеличением толщины пленки кобальта в графене накапливаются дефекты, т.к. сам механизм процесса интеркалирования напрямую связан с образованием дефектов. Увеличение концентрации дефектов проявляется в усилении диффузного фона картин ДМЭ, что хорошо видно из рис. $1, b$. Еще более наглядно этот эффект виден в спектрах КРС.

На рис. 6, $a$ представлен типичный спектр КРС исходных образцов, использованных в экспериментах по интеркалированию. В спектре наблюдаются особенности, возникающие при рассеянии света от графеновой пленки: линии $G$ и $2 D$. Малое значение ширины на половине высоты фононных линий $\left(F W H M_{G}=14.5 \mathrm{~cm}^{-1}\right.$ и $\left.F W H M_{2 D}=35 \mathrm{~cm}^{-1}\right)$, а также отсутствие в спектре линии $D$, природа которой обусловлена резонансным междолинным рассеянием света на оптическом фононе вблизи $K$ и $K^{\prime}$ точек зоны Бриллюэна с участием дефекта, указывают на хорошее качество исходных образцов графена. Было установлено, что форма линии $2 D$ в большинстве спектров исходных образцов имеет симметричный вид и хорошо аппроксимируется одиночным контуром Лоренца, что является признаком однослойного графена [30]. Форма линии 2D, которая может быть аппроксимирована огибающей четырех контуров Лоренца, наблюдается не более чем в 10\% от общего числа спектров, измеренных на исходных образцах. Из этих данных следует, что исходные образцы представляют собой преимущественно однослойный графен с небольшим количеством двухслойных включений.

Спектр КРС, измеренный после окончания первой серии экспериментов, в ходе которой пленка кобальта, нанесенная на поверхность образца при комнатной температуре, подвергалась 10-минутному отжигу при $800^{\circ} \mathrm{C}$, приведен на рис. $6, b$. В спектре детектируется низкочастотный сдвиг линий $G$ и $2 D$ и их уширение, a также наблюдается линия $D$, появление которой указывает на наличие структурных дефектов. Несмотря на уширение, которое мы связываем с возникновением структурных дефектов, контур линии $2 D$ по-прежнему хорошо аппроксимируется одиночным контуром Лоренца, что указывает на сохранение однослойности графеновой пленки. В работе [31] было показано, что из анализа таких параметров, как $F W H M$ линии $G$ и величина отношения интегральных интенсивностей $D$ и $G$ линий $\left(I_{D} / I_{G}\right)$ можно сделать заключение о типе дефектов в графене. Значение $F W H M_{G}=25 \mathrm{~cm}^{-1}$ и величина отношения $I_{D} / I_{G}=0.25$ указывают на то, что в обсуждаемом образце доминируют дефекты, связанные с границами кристаллитов. Из моделирования спектра, представленного на рис. $6, b$, на составляющие
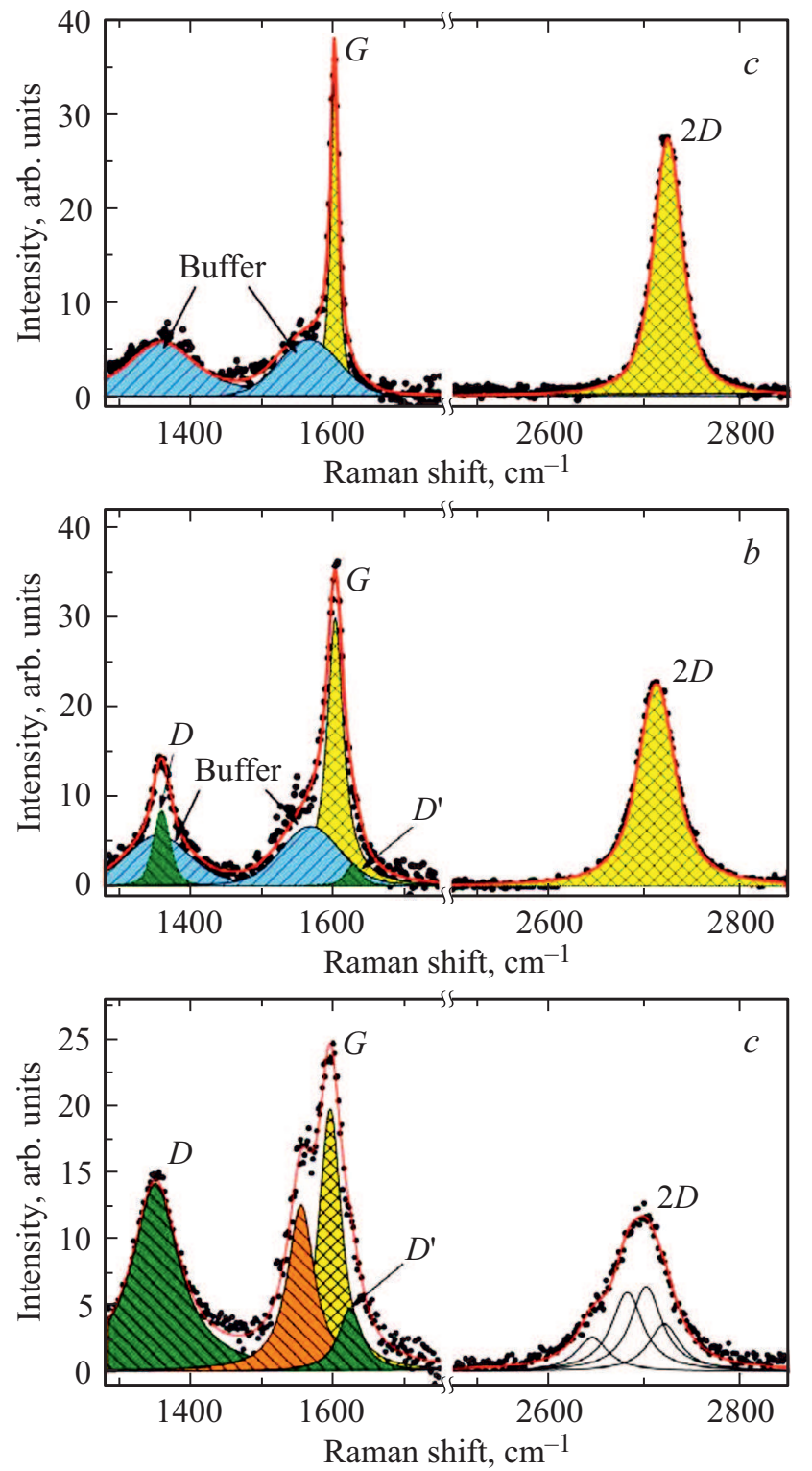

Рис. 6. Типичный спектр КРС для исходного образца $(a)$. Спектр КРС образца у которого пленка кобальта, нанесенная на его поверхность при комнатной температуре, подвергалась 10 -минутному отжигу при $800^{\circ} \mathrm{C}(b)$. Спектр КРС образца интеркалированного кобальтом $(c)$.

компоненты следует, что кроме линии $D$ в спектре присутствует еще слабая линия $D^{\prime}$, природа которой связана с внутри долинным рассеянием света на фононе вблизи точки $K$ зоны Бриллюэна с участием дефекта [30]. Тип дефектов в графене можно определять также с помощью анализа отношения интенсивностей линий $D$ и $D^{\prime}\left(I_{D} / I_{D^{\prime}}\right)$ [32]. Из анализа результатов моделирования интенсивностей компонент на рис. $6, b$ следует, что величина $\left(I_{D} / I_{D^{\prime}}\right)=3$, что подтверждает вывод о доминировании дефектов, связанных с границами кристаллитов в этом образце. 
В работе [33] было предложено выражение, позволяющее проводить оценку размера кристаллитов $\left(L_{a}\right)$

$$
L_{a}(\mathrm{~nm})=\left(2.4 \cdot 10^{-10}\right) \lambda_{l}^{4}\left(\frac{I_{D}}{I_{G}}\right)^{-1},
$$

здесь $\lambda_{l}=532 \mathrm{~nm}$ - длина волны лазера, используемого в наших экспериментах для возбуждения спектров КРС.

С использованием выражения (1) оценка среднего размера кристаллитов для образца у которого пленка кобальта, нанесенная на его поверхность при комнатной температуре подвергалась 10-минутному отжигу при $800^{\circ} \mathrm{C}$, составила $75 \mathrm{~nm}$.

Величина двуосной деформации в исходном образце и в образце с напыленным кобальтом может быть оценена из положения линии $2 D$ в спектре КРС [34]. Для исходного образца положение линии $2 D$ наблюдается на частоте $\omega_{2 D}=2723.5 \mathrm{~cm}^{-1}$, что соответствует деформации сжатия в плоскости слоя величиной $\varepsilon_{\|}=(0.32 \pm 0.03) \%$. После напыления и отжига линия $2 D$ регистрируется на частоте $\omega_{2 D}=2713.9 \mathrm{~cm}^{-1}$. Это свидетельствует о частичном снятии деформации, величина которой оценивается как $\varepsilon_{\|}=(0.27 \pm 0.03) \%$.

Спектр КРС, полученный для образца, процесс обработки которого, проводившийся при температуре $450^{\circ} \mathrm{C}$, привел к формированию пленки кобальта толщиной $1.7 \mathrm{~nm}$ под графеном, представлен на рис. 6,c. Видно, что процесс интеркалирования привел к существенным изменениям спектра КРС этого образца. Форма $2 D$ линии значительно изменилась - если в исходном образце она аппроксимировалась одиночным контуром Лоренца, то в интеркалированном образце ее форма описывается огибающей четырех контуров Лоренца. Подобная форма $2 D$ линии может возникнуть, если предположить, что в результате процесса интеркалирования буферный слой превращается во второй слой графена [35]. Такой процесс должен вести к нарушению ковалентных связей между буферным слоем и подложкой $\mathrm{SiC}$ и, как следствие, к значительному уменьшению деформации в графеновой пленке. Подтверждением этого является существенный низкочастотный сдвиг линии $2 D$ в спектре, который изменяется от значения $\omega_{2 D}=2723.5 \mathrm{~cm}^{-1}$, типичного для исходного образца, до $\omega_{2 D}=2694 \mathrm{~cm}^{-1}$, регистрируемого в спектре образца после интеркалирования кобальтом. К сожалению, надежные данные о коэффициенте деформационного сдвига линии $2 D$ в случае двуслойного графена отсутствуют в литературе. Однако с использованием имеющихся данных для однослойного графена [34] можно приблизительно оценить величину деформации в интеркалированном образце, которая составила $\varepsilon_{\|}=(0.14 \pm 0.02) \%$. Напомним, что величина двуосной деформации сжатия в исходных образцах была оценена как $\varepsilon_{\|}=(0.32 \pm 0.03) \%$.

Процесс моделирования выявил также значительное уширение $G$ линии и существенный рост интенсивностей $D$ и $D^{\prime}$ линий в спектре КРС интеркалированного образца. Значение $F W H M_{G}=41 \mathrm{~cm}^{-1}$ и величина отношения интенсивностей $I_{D} / I_{G}=1.56$ указывают на то, что в образце после интеркалирования доминируют точечные дефекты [31]. На наличие именно точечных дефектов указывает и величина отношения интенсивностей $\left(I_{D} / I_{D^{\prime}}\right)=6[32]$.

В работе [36] было предложено выражение, позволяющее проводить оценку концентрации точечных дефектов в графене

$$
n_{D}=\frac{4.3 \cdot 10^{13}}{E_{L}^{4}}\left(\frac{I_{D}}{I_{G}}\right)^{-1},
$$

где $E_{L}=2.33 \mathrm{eV}$. С использованием выражения (2) было рассчитано значение концентрации точечных дефектов в образце после его интеркалирования кобальтом, которое составило $9.3 \cdot 10^{11} \mathrm{~cm}^{-2}$.

Еще одной отличительной чертой спектра КРС интеркалированного образца является появление особенности на низкочастотном крыле линии $G$. В модельном спектре эта особенность представлена одиночной линией на частоте $1554 \mathrm{~cm}^{-1}$. Силицид кобальта, образование которого было выявлено в этом образце методом ФЭС, не имеет таких высоких частот в спектре КРС. Возможно, что в результате химической реакции кобальта с графеном образовалось соединение на основе углерода, которое в принципе может иметь такую высокую частоту в спектре. Чтобы ответить на этот вопрос окончательно, требуются дальнейшие исследования.

Таким образом, анализ спектров КРС показал, что если высокотемпературный отжиг образца $\left(800^{\circ} \mathrm{C}\right)$ приводит, преимущественно, к усилению дефектов, связанных с границами кристаллитов в слое графена, то процесс интеркалирования его кобальтом при температуре $450^{\circ} \mathrm{C}$ сопровождается резким увеличением концентрации точечных дефектов. Этот результат согласуется с рассмотренными выше данными ДМЭ. Обнаруженная методом КРС трансформация буферного слоя во второй слой графена, стимулированная интеркаляцией кобальта, подтверждается данными ФЭС. При дозах интеркалирования более $1 \mathrm{~nm}$ Со интенсивность моды $G$ в $\mathrm{C} 1 s$ спектрах становится выше, чем в спектре исходного образца.

Обратимся теперь к результатам исследования магнитных свойств пленок кобальта, сформированных под графеном, которые были получены методом МЛД, основанным на зависимости формы линии фотовозбужденных Со $3 p$ электронов от направления намагниченности образца [37-40]. Причиной возникновения такой зависимости является энергетическое расщепление возбуждаемого спин-орбитального дублета на подуровни с различными магнитными квантовыми числами, обусловленное взаимодействием остовного уровня с магнитополяризованной валентной зоной.

Типичные спектры Co $3 p$ электронов, измеренные для пленок разной толщины, показаны на рис. 7, $a$. Каждый из спектров был получен для двух противоположных направлений намагниченности образца $I_{\text {up }}(E)$ и $I_{\text {down }}(E)$. Видно, что спектры $I_{\text {up }}(E)$ и $I_{\text {down }}(E)$, 


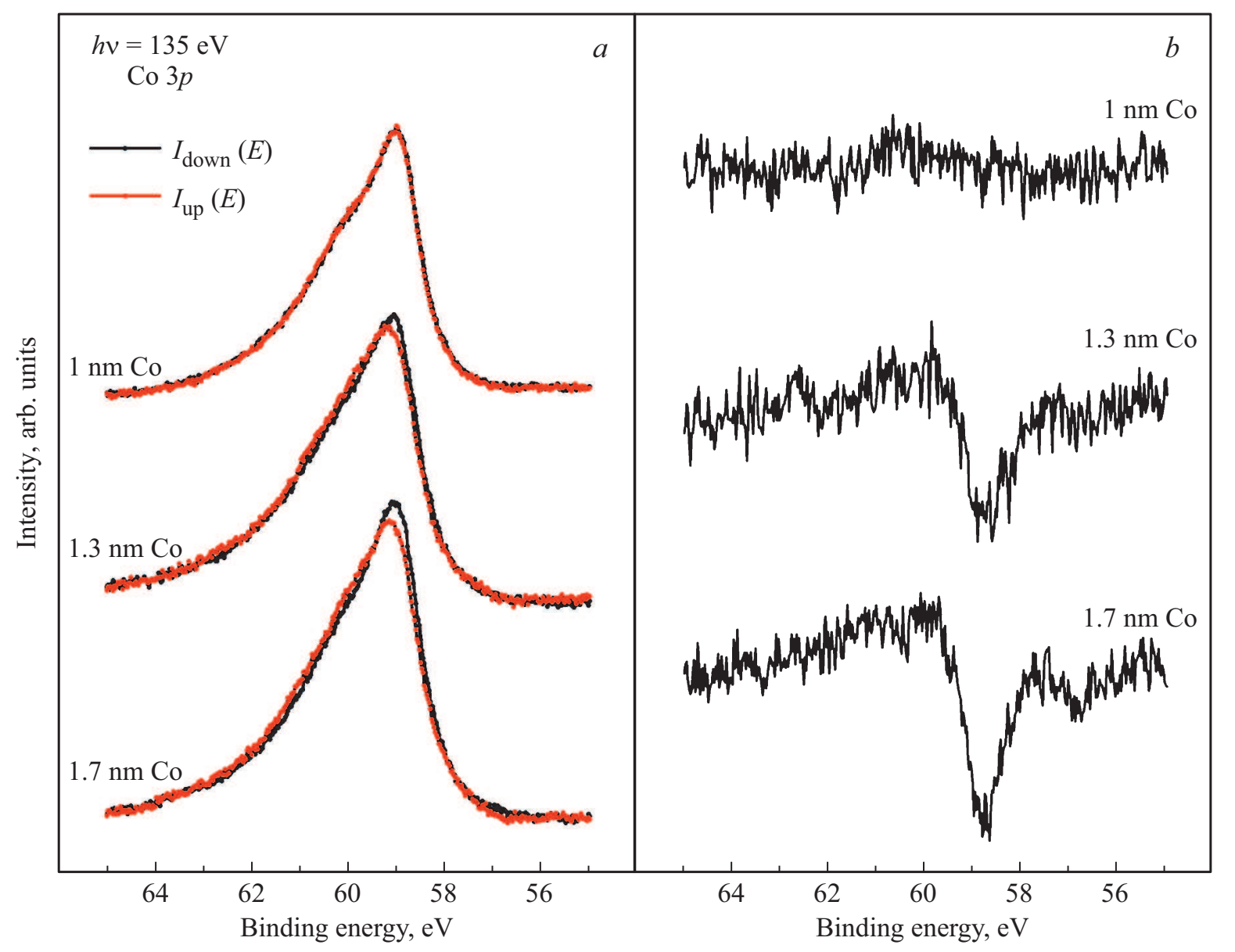

Рис. 7. Спектры Со $3 p$, измеренные для двух противоположных направлений намагниченности образца $(a)$, и соответствующие им разностные кривые $(b)$.

соответствующие самой тонкой пленке $(1.0 \mathrm{~nm})$, практически совпадают. Выявить их слабые различия могут помочь разностные кривые $I_{\text {up }}(E)-I_{\text {down }}(E)$. Однако и разностная кривая (рис. $7, b$ ), соответствующая данным спектрам, демонстрирует лишь белый шум. Отсутствие эффекта МЛД обусловлено перпендикулярной магнитной анизотропией данной пленки, препятствующей ее намагничиванию вдоль поверхности.

Порог переориентации вектора намагниченности тонких пленок кобальта (Spin reorientation transition [41]), происходящий с увеличением их толщины, обычно наблюдается при $\sim 0.6 \mathrm{~nm}$ [42]. Поэтому, хотя толщина слоя кобальта $(1 \mathrm{~nm})$ и значительно превосходит указанный порог, графен, покрывающий пленку, оказывает стабилизирующее влияние на ее перпендикулярную магнитную анизотропию. Сделанный вывод подтверждается результатами недавней работы [8], авторы которой исследовали магнитные свойства интеркаляционной системы графен-кобальт-иридий и обнаружили, что переориентация вектора намагниченности пленок происходит в аномально широком диапазоне толщин (от 12 до 24 монослоев). Сходный, но значительно менее выраженный эффект влияния графена на магнитные свойства интеркалированной пленки железа наблюдался и для системы графен-железо-никель [17].

Спектры $I_{\text {up }}(E)$ и $I_{\text {down }}(E)$ (рис. 7, $\left.a\right)$, измеренные для более толстой пленки Со (толщиной $1.3 \mathrm{~nm}$ ), уже демонстрируют определенные различия. Появление в этом случае эффекта МЛД особенно заметно на разностной кривой, в которой возникает минимум при энергии $58.5 \mathrm{eV}$, соответствующий подуровню $m_{j}=-3 / 2$ расщепленного мультиплета Со $3 p$ [43]. Для более толстого слоя $(1.7 \mathrm{~nm})$ интеркалированного кобальта этот минимум становится еще сильнее (рис. $7, b$ ), что указывает на ферромагнитное упорядочение пленки вдоль поверхности образца. Именно такая магнитная анизотропия пленок кобальта под графеном наблюдалась в работе [26].

\section{4. Заключение}

В настоящей работе впервые исследован процесс интеркалирования кобальтом графена, выращенного на поверхности $4 H$-SiC(0001). Методами фотоэлектронной спектроскопии высокого энергетического разрешения с использованием синхротронного излучения и дифракции медленных электронов изучена эволюция атомного 
строения, элементного и фазового состава системы $\mathrm{Gr} / \mathrm{Co} / \mathrm{SiC}$, а также ее магнитных свойств с увеличением дозы интеркалирования и с повышением температуры.

Показано, что в отличие от пленок железа отжиг пленок кобальта, нанесенных на графен при комнатной температуре, не приводит к интеркалированию графена кобальтом. Формирование интеркаляционной системы $\mathrm{Gr} / \mathrm{Co} / \mathrm{SiC}$ происходит лишь при нанесении атомов Со на образцы, нагретые до температуры выше $\sim 400^{\circ} \mathrm{C}$. При температурах более $500^{\circ} \mathrm{C}$ рост пленок кобальта под графеном лимитируется диффузией кобальта в объем карбида кремния. Таким образом, оптимальные условия синтеза пленок кобальта реализуются при температуре, равной $\sim 450^{\circ} \mathrm{C}$. В этом режиме под графеном были сформированы ферромагнитные слои кобальта толщиной до $2 \mathrm{~nm}$ и показано, что они намагничиваются вдоль поверхности при толщинах более $1.3 \mathrm{~nm}$.

\section{Благодарности}

Авторы благодарят Российско-Германскую лабораторию на BESSY II и Helmholtz-Zentrum Berlin за возможность использования синхротронного излучения.

\section{Финансирование работы}

Работа выполнена в рамках госзадания ФГБУН Физико-технический институт им. А.Ф. Иоффе (тема № 14.21). Автор Е.Ю.Л. Поддержана грантом Минобрнауки РФ (задание 3.3161.2017/4.6 проектной части госзадания).

\section{Конфликт интересов}

Авторы заявляют, что у них нет конфликта интересов.

\section{Список литературы}

[1] K.V. Emtsev, A. Bostwick, K. Horn, J. Jobst, G.L. Kellogg, L. Ley, J.L. Mc Chesney, T. Ohta, S. A. Reshanov, J. Rohrl, E. Rotenberg, A.K. Schmid, D. Waldmann, H.B. Weber, T. Seyller. Nature Mater. 8, 203 (2009).

[2] G.R. Yazdi, T. Iakimov, R. Yakimova. Crystals 6, 53 (2016).

[3] C. Riedl, C. Coletti, T. Iwasaki, A.A. Zakharov, U. Starke. Phys. Rev. Lett. 103, 246804 (2009).

[4] I. Gierz, T. Suzuki, R.T. Weitz, D.S. Lee, B. Krauss, C. Riedl, U. Starke, H. Höchst, J.H. Smet, C.R. Ast, K. Kern. Phys. Rev. B 81, 235408 (2010).

[5] K. Li, X. Feng, W. Zhang, Y. Ou, L. Chen, K. He, L. Wang, L. Guo, G. Liu, Q. Xue, X. Ma. Appl. Phys. Lett. 103, 062601 (2013).

[6] M. Weser, Y. Rehder, K. Horn, M. Sicot, M. Fonin, A.B. Preobrajenski, E. Voloshina, E. Goering, Y.S. Dedkov. Appl. Phys. Lett. 96, 012504 (2010).

[7] R. Decker, J. Brede, N. Atodiresei, V. Caciuc, S. Blugel, R. Wiesendanger. Phys. Rev. B 87, 041403 (2013).

[8] A.D. Vu, J. Coraux, G. Chen, A.T. N'Diaye, A.K. Schmid, N. Rougemaille. Sci. Rep. 6, 24783 (2016).
[9] H. Yang, A.D. Vu, A. Hallal, N. Rougemaille, J. Coraux, G. Chen, A.K. Schmid, M. Chshiev. Nano Lett. 16, 145 (2016).

[10] H. Yang, A. Cotta, A.T. N`Diaye, S.A. Nikolaev, E.A. Soares, W.A.A. Macedo, K. Liu, A.K. Schmid, A. Fert, M. Chshiev. Nature Mater. 17, 605 (2018).

[11] W. Han, R.K. Kawakami, M. Gmitra, J. Fabian. Nature Nanotechnol. 9, 794 (2014).

[12] E.A. Soares, G.J.P. Abreu, S.S. Carara, R. Paniago, V.E. de Carvalho, H. Chacham. Phys. Rev. B 88, 165410 (2013).

[13] H. Vita, S. Bottcher, P. Leicht, K. Horn, A.B. Shick, F. Maca. Phys. Rev. B 90, 165432 (2014).

[14] D. Pacile, S. Lisi, I. Di Bernardo, M. Papagno, L. Ferrari, M. Pisarra, M. Caputo, S.K. Mahatha, P.M. Sheverdyaeva, P. Moras, P. Lacovig, S. Lizzit, A. Baraldi, M.G. Betti, C. Carbone. Phys. Rev. B 90, 195446 (2014).

[15] M. Cattelan, G. W. Peng, E. Cavaliere, L. Artiglia, A. Barinov, L.T. Roling, M. Favaro, I. Piš, S. Nappini, E. Magnano, F. Bondino, L. Gavioli, S. Agnoli, M. Mavrikakis, G. Granozzi. Nanoscale 7, 2450 (2015).

[16] R. Friedrich, V. Caciuc, N. Atodiresei, S. Bluëgel. Phys. Rev. B 93, 220406(R) (2016).

[17] G.S. Grebenyuk, O.Yu. Vilkov, A.G. Rybkin, M.V. Gomoyunova, B.V. Senkovskiy, D.Yu. Usachov, D.V. Vyalikh, S.L. Molodtsov, I.I. Pronin. Appl. Surf. Sci. 392, 715 (2017).

[18] М.В. Гомоюнова, Г.С. Гребенюк, Д.А. Смирнов, И.И. Пронин. ФТТ 59, 2027 (2017).

[19] G.S. Grebenyuk, S.M. Dunaevsky, E.Yu. Lobanova, D.A. Smirnov, I.I. Pronin. Appl. Surf. Sci. 470, 840 (2019).

[20] S.J. Sung, J.W. Yang, P.R. Lee, J.G. Kim, M.T. Ryu, H.M. Park, G. Lee, C.C. Hwang, K.S. Kim, J.S. Kim, J.W. Chung. Nanoscale 6, 382 (2014).

[21] K. Shen, H. Sun, J. Hu, J. Hu, Z. Liang, H. Li, Z. Zhu, Y. Huang, L. Kong, Y. Wang, Z. Jiang, H. Huang, J.W. Wells, F. Song. J. Phys. Chem. C 122, 37, 21484 (2018).

[22] М.В. Гомоюнова, Г.С. Гребенюк, В.Ю. Давыдов, И.А. Ермаков, И.А. Елисеев, А.А. Лебедев, С.П. Лебедев, Е.Ю. Лобанова, А.Н. Смирнов, Д.А. Смирнов, И.И. Пронин. ФТТ 60, 1423 (2018).

[23] W. Chen, K.P. Loh. Appl. Phys. Lett. 84, 281 (2004)

[24] L.H. de Lima, R. Landers, A. de Siervo. Chem. Mater. 26, 14, 4172 (2014).

[25] Y. Zhang, H. Zhang, Y. Cai, J. Song, P. He. Nanotechn. 28 075701 (2017).

[26] R. Hönig, P. Roese, K. Shamout, T. Ohkochi, U. Berges, C. Westphal. Nanotechn. 30, 025702 (2019).

[27] В.Ю. Давыдов, Д.Ю. Усачёв, С.П. Лебедев, А.Н. Смирнов, В.С. Левицкий, И.А. Елисеев, П.А. Алексеев, М.С. Дунаевский, О.Ю. Вилков, А.Г. Рыбкин, А.А. Лебедев. ФТП 51, 1116 (2017).

[28] C. Riedl, C. Coletti, U. Starke. J. Phys. D 43, 374009 (2010).

[29] K.V. Emtsev, F. Speck, T. Seyller, L. Ley. Phys. Rev. B 77, 155303 (2009).

[30] A.C. Ferrari, D.M. Basko. Nature Nanotech. 8, 235 (2013).

[31] L.G. Cançado, M.G. daSilva, E.H. Martins Ferreira, F. Hof, K. Kampioti, K. Huang, A. Pénicaud, C.A. Achete, R.B. Capaz, A. Jorio. 2D Mater. 4, 025039 (2017).

[32] A. Eckmann, A. Felten, A. Mishchenko, L. Britnell, R. Krupke, K.S. Novoselov, C. Casiraghi. Nano Lett. 12, 8, 3925 (2012).

[33] L.G. Cançado, K. Takai, T. Enoki, M. Endo, Y.A. Kim, H. Mizusaki, A. Jorio, L.N. Coelho, R. Magalhaes-Paniago, M.A. Pimenta. Appl. Phys. Lett. 88, 16, 163106 (2006). 
[34] F. Ding, H. Ji, Y. Chen, A. Herklotz, K. Dorr, Y. Mei, A. Rastelli, O.G. Schmidt. Nano Lett. 10, 3453 (2010).

[35] A.C. Ferrari, J.C. Meyer, V. Scardaci, C. Casiraghi, M. Lazzeri, F. Mauri, S. Piscanec, D. Jiang, K.S. Novoselov, S. Roth, A.K. Geim. Phys. Rev. Lett. 97, 187401 (2006).

[36] M.M. Lucchese, F. Stavale, E.H. Martins Ferreira, C. Vilani, M.V.O. Moutinho, R.B. Capaz, C.A. Achete, A. Jorio. Carbon 48, 1592 (2010).

[37] Ch. Roth, F.U. Hillebrecht, H.B. Rose, E. Kisker. Phys. Rev. Lett. 70, 3479 (1993).

[38] F. Sirotti, G. Rossi. Phys. Rev. B 49, 15682 (1994).

[39] N. Janke-Gilman, M. Hochstrasser, R.F. Willis. Phys. Rev. B 70, 184439 (2004).

[40] I.I. Pronin, M.V. Gomoyunova, D.E. Malygin, D.V. Vyalikh, Yu.S. Dedkov, S.L. Molodtsov. J. Appl. Phys. 104, 104914 (2008).

[41] J.-W. Lee, J.-R. Jeong, S.-C. Shin, J. Kim, S.-K. Kim. Phys. Rev. B 66, 172409 (2002).

[42] И.И. Пронин, М.В. Гомоюнова, С.М. Соловьев, О.Ю. Вилков, Д.В. Вялых. ФТТ 53, 573 (2011).

[43] F. Sirotti, G. Rossi. Phys. Rev. B 49, 15682 (1994).

Редактор К.В. Емцев 